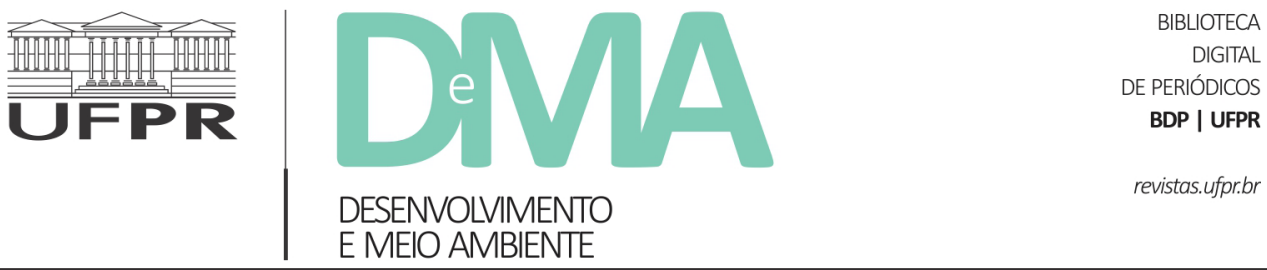

\title{
A governança nexo água, energia e alimentos e os espaços públicos de participação social: um estudo aplicado ao contexto do Sistema Produtor de Água Cantareira
}

\section{Governance nexus water, energy and food and public spaces for social participation: a study applied to the context of the Cantareira Water Producing System}

\author{
Rafael Eduardo CHIODI ${ }^{1 *}$, Samuel Mello PINTO ${ }^{2}$, Alexandre UEZU ${ }^{3}$ \\ ${ }^{1}$ Universidade Federal de Lavras (UFLA), Lavras, MG, Brasil. \\ ${ }^{2}$ Universidade de São Paulo (USP), Piracicaba, SP, Brasil. \\ ${ }^{3}$ Instituto de Pesquisas Ecológicas, Nazaré Paulista, SP, Brasil. \\ *E-mail de contato: rafaelchiodi@ufla.br
}

Artigo recebido em 8 de abril de 2020, versão final aceita em 27 de novembro de 2020, publicado em 26 de julho de 2021.

RESUMO: A abordagem nexo água, energia e alimentos reconhece as interconexões entre os sistemas hídrico, energético e alimentar, e, para que a gestão integrada destes seja eficiente e sustentável, propõe que ocorra dentro de processos de governança. No Brasil, os espaços de participação para a gestão de políticas públicas estabelecem arranjos institucionais potenciais para abrigar a governança nexo. Partindo desta compreensão, olhou-se para um dos contextos mais críticos à segurança hídrica do país, a área dos mananciais do Sistema Cantareira. Nele o nexo é compreendido a partir das inter-relações entre a produção de alimentos (leite e carne), de bioenergia (lenha e carvão) e a segurança hídrica. $\mathrm{O}$ artigo considera características dos espaços públicos voltados à gestão participativa de políticas ambientais e de desenvolvimento rural sustentável para analisar se seus arranjos institucionais permitiriam comportar um processo de governança nexo delimitado pela área de contribuição dos reservatórios do Sistema Cantareira. Para a pesquisa foram utilizados dados secundários para a análise documental (leis, atas, documentos técnicos) e primários coletados em entrevistas junto a atores que participavam destes espaços. Os espaços públicos focados foram os conselhos gestores municipais, os conselhos de unidades de conservação e o comitê de bacia hidrográfica. Apesar de possuírem características desejáveis a um processo de governança nexo, como contarem com múltiplos atores e terem caráter participativo, nenhum dos arranjos analisados comportaria tal proposta. Além de não terem como escala exclusiva de atuação a área dos mananciais do Sistema Cantareira, estes espaços são orientados por 
objetivos setoriais e não engajam produtores de alimentos e de bioenergia. Desse modo, construir a governança nexo água, energia e alimentos exigiria esforços para adequar o espaço que mais apresenta características favoráveis, o comitê de bacia hidrográfica.

Palavras-chave: desenvolvimento; sustentabilidade; instituições participativas.

ABSTRACT: The water, energy and food nexus approach recognize the interconnections between water, energy and food systems and, in order for their integrated management to be efficient and sustainable, proposes that it occur within governance processes. In Brazil, participation spaces for public policy management establish potential institutional arrangements to house the governance nexus. Based on this understanding, one of the most critical contexts for water security in the country was the area of the sources of the Cantareira System. In it, the nexus is understood from the inter-relationships between the production of food (milk and meat), bioenergy (firewood and coal) and water security. The article considers characteristics of public spaces aimed at the participatory management of environmental policies and sustainable rural development to analyze whether their institutional arrangements would allow for a nexus governance process delimited by the area of contribution of the reservoirs of the Cantareira System. For the research, secondary data were used for documental analysis (laws, minutes, technical documents) and primary data collected in interviews with actors who participated in these spaces. The public spaces focused on municipal management councils, the conservation unit councils, and the watershed committee. Despite having desirable characteristics to a process of nexus governance, such as having multiple actors and having a participative character, none of the arrangements analyzed would carry such proposal. In addition to not having as an exclusive scale of action the area of the Cantareira System, these spaces are guided by sectorial objectives and do not engage food and bioenergy producers. Thus, building governance nexus water, energy and food would require efforts to adapt the space that presents the most favorable characteristics, the watershed committee.

Keywords: development; sustainability; participatory institutions.

\section{Introdução}

A abordagem nexo água, energia e alimentos (nexus water, energy and food) emergiu na última década em torno de preocupações com as tendências mundiais de aumento populacional, de crescimento econômico e de mudanças climáticas que vêm colocando sobre pressão estes recursos que são vitais. Ela parte da interpretação de que os modelos vigentes para promover a gestão setorial destes recursos não são efetivos em dar respostas que garantam maiores níveis de segurança hídrica, energética e alimentar às sociedades (Hoff, 2011; Flammini et al., 2014; Giatti et al., 2016)
Diante disso, a abordagem nexo propõe a compreensão das interações que ocorrem entre os sistemas humanos e naturais em torno dos recursos água, energia e alimentos. Com foco no reconhecimento das interconexões entre estes recursos e seus sistemas, visa subsidiar intervenções técnicas e de cunho político-institucional, pretendendo um desenvolvimento mais seguro e sustentável (Flammini et al., 2014).

As intervenções com base no nexo devem ocorrer dentro de processos de governança. A governança nexo pressupõe a existência de instituições formais e informais que influenciam políticas e tomada de decisões integradas entre os provedores de água, de energia e de alimentos (Scott, 2017). 
Assim, procura estabelecer e organizar esferas de diálogos que promovam o engajamento de atores sociais (Flammini et al., 2014). Então, a governança nexo prescinde de arranjos institucionais que comportem objetivos multicêntricos, que sejam multisetoriais e abriguem múltiplos atores, sendo orientados por escalas espaciais apropriadas aos objetivos nexo, estes necessitam impor alta intensidade de participação social (Flammini et al., 2014; Benson et al., 2015).

Neste sentido, a abordagem nexo está sendo mobilizada para oportunizar novas perspectivas para a governança dos recursos naturais no contexto dos mananciais do Sistema Produtor de Água Cantareira, o maior sistema de abastecimento da Região Metropolitana de São Paulo. O intuito geral é aferir a pertinência e a viabilidade da abordagem nexo como um novo modelo de governança que possa ser apropriado pelos atores sociais engajados na promoção do desenvolvimento sustentável neste contexto.

Neste cenário, o nexo água, energia e alimentos remete às inter-relações que ocorrem no âmbito do uso e da ocupação do solo. Em 2011, a área dos mananciais do Sistema Cantareira estava ocupada em aproximadamente $46 \%$ por pastagens, e em $16 \%$ por monoculturas de eucalipto (Uezu et al., 2017). A pastagem sustenta a pecuária bovina que produz leite e carne, e os plantios de eucalipto se destinam prioritariamente à produção de carvão e lenha. Estas atividades apresentam um dinâmica de inter-relação particular, uma se configurando em alternativa produtiva à outra. Além de atividades centrais à economia rural, afetam sobremaneira variáveis hidrológicas e, por consequência, a segurança hídrica regional (Chiodi et al., 2019).
No campo político-institucional, várias instituições e atores ganharam relevância nas últimas décadas na região. Os princípios constitucionais da descentralização e da participação permitiram que várias políticas públicas fossem geridas dentro de novos arranjos institucionais, apropriados à participação social (Dagnino, 2002; Jacobi, 2003). Como resultado, uma multiplicidade de atores atraídos por problemáticas socioambientais passou a se encontrar em espaços públicos de elaboração e gestão de políticas públicas (Chiodi et al., 2019).

Neste contexto, o artigo considera características dos espaços públicos voltados à gestão participativa de políticas ambientais e de desenvolvimento rural sustentável para analisar se seus arranjos institucionais permitiriam comportar um processo de governança nexo delimitado pela área de contribuição dos reservatórios do Sistema Cantareira. Para tanto, 1) estabelece o arcabouço teórico que apresenta as características desejáveis para um arranjo institucional apropriado à governança nexo; 2) delimita o contexto nexo na área dos mananciais do Sistema Cantareira; 3) descreve as características dos conselhos municipais, dos conselhos de unidades de conservação e do comitê de bacia hidrográfica identificados neste contexto; e 4) discute e analisa se estes se ajustam às características desejáveis para que aconteça a governança focada no nexo água, energia e alimentos.

\section{Metodologia}

O trabalho se inscreve no campo da análise de políticas públicas. O ponto de partida é a teoria institucional, uma corrente de estudos da ciência política que enfatiza o papel das instituições sobre 
o comportamento dos atores sociais. Mais especificamente, mobiliza-se a vertente neo-institucional que enfatiza a importância crucial das instituições/ regras para a decisão, formulação e implementação de políticas públicas, mas assume como relevante os papeis, os interesses e as ações dos atores sociais (Hall \& Taylor, 2003).

Orientado por este campo teórico, procedeu-se uma aproximação que levou à utilização da abordagem nexo água, energia e alimentos (Flammini et al., 2014) como instrumento teórico-analítico para analisar os espaços públicos de participação social no âmbito de políticas públicas. Aqui, conforme Keskinen et al. (2015), o nexo se constitui em uma abordagem para pesquisa e análise, além de uma ferramenta que pode subsidiar a elaboração de políticas públicas. Desse modo, o artigo contribui para a reflexão das possibilidades que as instituições abrem para abrigar um processo de governança nexo no contexto do Sistema Cantareira ${ }^{1}$, buscando apontar limitações e oportunidades que os espaços públicos de participação permitem para tanto.

Neste sentido, partiu-se do que se entende como o "contexto do Sistema Cantareira", uma vez que para a abordagem nexo ser posta em prática a delimitação de uma escala espacial se faz necessária, assim, as problemáticas inter-relacionadas serão identificadas, os atores sociais se mobilizarão diante delas e as intervenções serão executadas e avaliadas em um espaço determinado (Flammini et al., 2014).

Partindo desta delimitação, definiu-se o contexto do Sistema Cantareira como sendo a área dos mananciais dos seus reservatórios, ou mais preci- samente, os nove municípios que perfazem 98,1\% dessa área, a saber: Camanducaia, Extrema, Itapeva e Sapucaí-Mirim, em Minas Gerais; e Joanópolis, Mairiporã, Nazaré Paulista, Piracaia e Vargem, em São Paulo (Figura 1) (Uezu et al., 2017).

Com o recorte destes municípios, identificou-se os espaços públicos de participação social relacionados à gestão de políticas públicas de cunho ambiental e de desenvolvimento rural. Esta etapa ocorreu através de buscas em sites das prefeituras municipais, de órgãos estaduais (institutos estaduais de florestas e órgãos de assistência técnica e extensão rural) e federais (Agência Nacional de Águas e Ministério do Meio Ambiente).

A definição das características desejáveis aos arranjos institucionais aptos à governança nexo água, energia e alimentos foi subsidiada por literatura internacional, tendo como referência fundamental o documento elaborado por Flammini et al. (2014) no âmbito da Organização das Nações Unidas para Alimentação. Também por meio de literatura científica e de documentos técnicos foi delimitado o contexto de análise nexo no contexto do Sistema Cantareira.

Os espaços públicos foram caracterizados através de análise documental e de pesquisa de campo. A análise documental (leis, decretos, atas de reuniões e documentos técnicos) foi o meio pelo qual identificaram-se as características dos espaços públicos, tais como objetivos institucionais, composições de representação, entidades representadas na gestão vigente, periodicidade das reuniões e caráter decisório (consultivo/deliberativo). ${ }^{1}$ Vincula-se ao projeto: “Água, energia e alimentos: aplicação da abordagem nexus para contribuir com a gestão dos recursos naturais na área
de contribuição do Sistema Produtor de Água Cantareira” (CNPq 441244/2017-3]. 


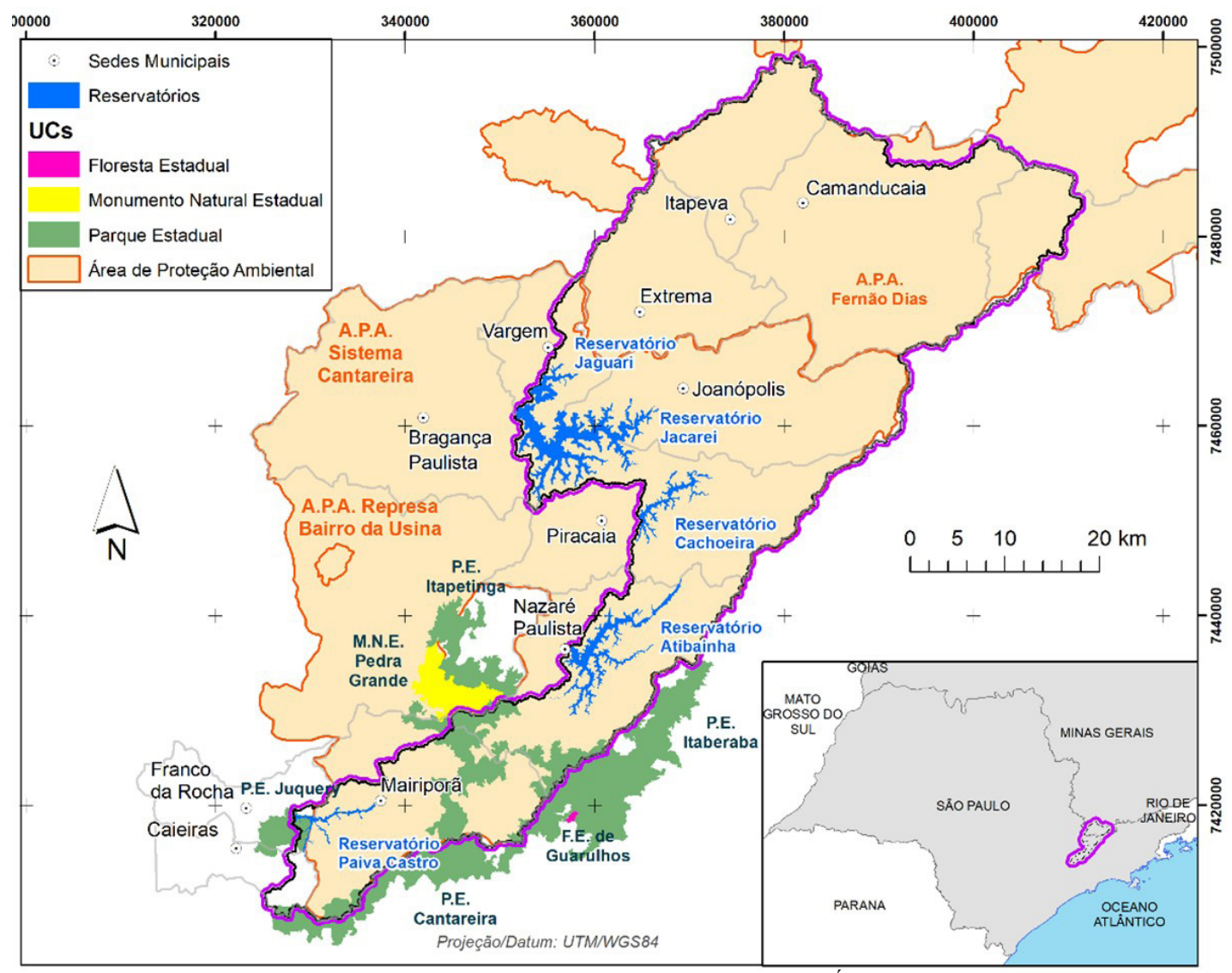

FIGURA 1 - Delimitação da área de contribuição dos reservatórios do Sistema Produtor de Água Cantareira com a subdivisão dos territórios dos municípios do estado de São Paulo e de Minas Gerais e das unidades de conservação, Brasil, 2020.

FONTE: Elaborado pelos autores.

Na pesquisa de campo foram entrevistados por meio de roteiro semiestruturado (Richardson, 2010) membros dos conselhos municipais (Camanducaia, Itapeva, Extrema, Sapucaí-Mirim, Joanópolis, Mairiporã e Nazaré Paulista), dos conselhos de unidades de conservação (Área de Proteção Ambiental-APA Fernão Dias, APA Cantareira, APA Piracicaba Juqueri-Mirim, Parque Estadual-PE de Itapetinga e PE Itaberaba) e do Comitê das Bacias Hidrográficas dos Rios Piracicaba, Capivari e Jundiaí (Comitê
PCJ). As entrevistas foram gravadas e transcritas. Com base nas transcrições foi possível identificar características mais particulares da percepção dos entrevistados, considerando a efetividade dos espaços para processos de tomadas de decisões e para as formas de articulação entre atores sociais em curso nestes espaços.

De modo complementar, coletou-se dados por meio de observação não participante (Richardson, 2010) em 11 reuniões do Comitê PCJ e em uma 
reunião do conselho gestor da APA Cantareira. A presença dos pesquisadores nas reuniões objetivou compreender como o contexto do Sistema Cantareira era tratado naquele espaço, além de captar dinâmicas de funcionamento e interesses dos atores.

Para ampliar as possibilidades de análise foram tratados dados coletados em atas das reuniões do Comitê PCJ e informações públicas disponíveis da sua gestão 2017-2019. Quando disponíveis, as atas dos conselhos municipais (de meio ambiente e de desenvolvimento rural) e das unidades de conservação foram consideradas. A organização dos dados pretendeu a obtenção de informações quantitativas e qualitativas.

A pesquisa de campo e a análise documental subsidiaram a inferência sobre a "intensidade de participação" dos espaços em foco. Conforme Flammini et al. (2014), a intensidade de participação dos atores se relaciona com os níveis, as técnicas e os tipos de impactos da participação, podendo estar dentro de um gradiente que vai de "baixa" a "alta" intensidade. A Tabela 1 mostra os indicadores considerados para a classificação.

Com base na Tabela 1, depreende-se que a "intensidade de participação" partiu de indicadores qualitativos. O "nível de participação" foi captado na própria legislação que criou e regulamentou os conselhos (se consultivo e/ou deliberativo); as "técnicas de participação" foram identificadas em sua presença/ausência por análise documental e em entrevistas, não havendo a quantificação dos dados; e os "tipos de impactos", o indicador mais subjetivo, foi definido através dos níveis de participação, da existência de estruturas decisórias, do caráter propositivo e da autonomia financeira que refletem em efetiva mudança no uso e ocupação do solo regional.

TABELA 1 - Visão geral das características da participação social.

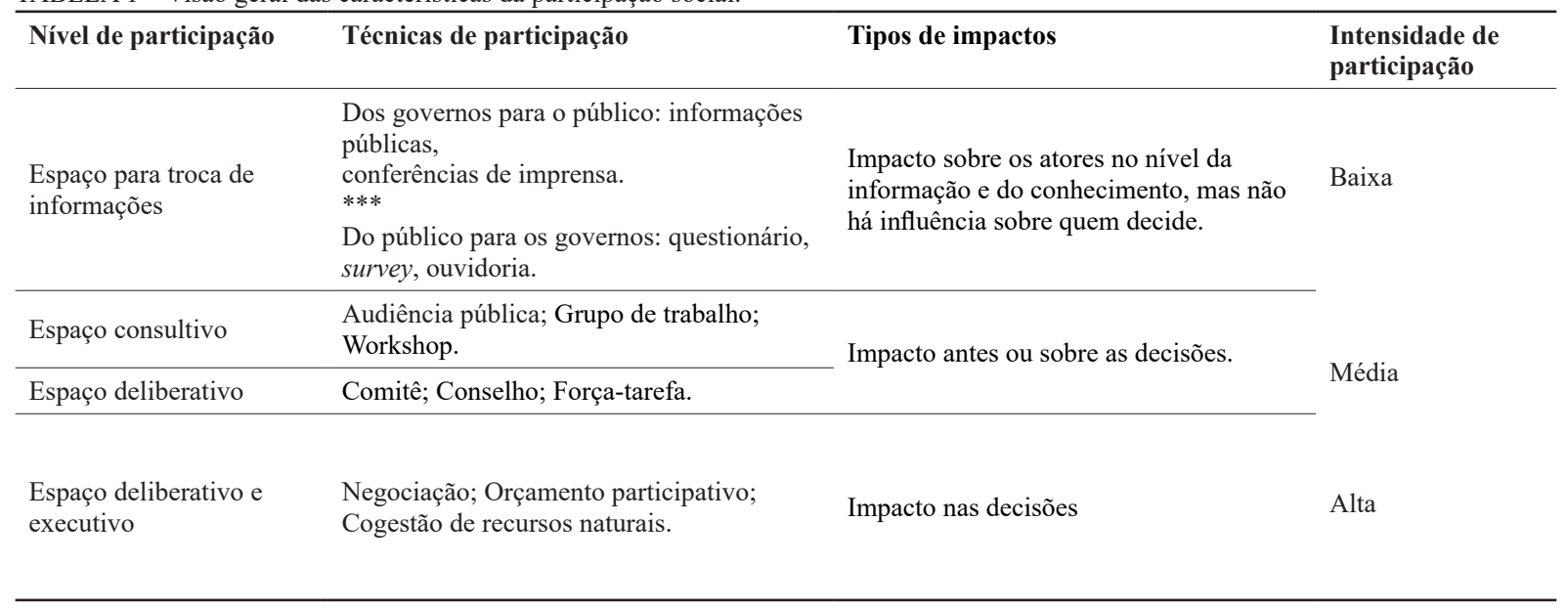

FONTE: Adaptado de Flammini et al. (2014). 


\section{A governança nexo água, energia e alimentos}

O reconhecimento das interdependências entre os sistemas hídrico, energético e alimentar surge como uma concepção inovadora, pois estabelece que a partir da compreensão das interconexões na base destes recursos, que inclui terra, água, energia, capital e trabalho, as intervenções de resposta serão as mais eficientes e sustentáveis possíveis, reduzindo trocas conflitivas (trade-off) e elevando sinergias entre os sistemas (Hoff, 2011; Flammini et al., 2014; Giatti et al., 2016).

A literatura demonstra a relevância da dimensão da governança para que nexo possa ter efetividade. Ou seja, muitos dos desafios para a efetivação da abordagem não se encontram na elaboração de novos instrumentos técnicos (Märker et al., 2018), mas na construção de novos processos políticos e institucionais (Giatti et al., 2016; Rasul \& Sharma, 2016; Pahl-Wostl, 2017; Weitz et al., 2017).

Pahl-Wostl (2017) entende que a governança nexo possa se constituir por uma ampla noção de governança, a qual envolva os sistemas político, social, econômico e administrativo que determinam o uso e o fornecimento de bens e serviços relacionados aos recursos água, energia e alimentos. No nível institucional, a governança nexo reconhece o papel das instituições (regras de mercado, regulamentos, normas sociais), dos atores (famílias, organizações, empresas, governo) e das ações (políticas, comportamentos) dentro dos diferentes sistemas (Pahl-Wostl, 2009).

Portanto, para que as intervenções nexo tenham impactos de longo prazo, estas deverão ocorrer como parte de dinâmicas de engajamento e de diálogo entre os atores (Stakeholder dialogue). Desse modo, para pôr em prática a abordagem nexo prescinde-se de arranjos institucionais adequados. Tais arranjos necessitam de características específicas para que a governança nexo se efetive (Flammini et al., 2014).

Dos arranjos institucionais para abrigar a governança nexo esperam-se as seguintes características: objetivos que integrem os interesses de diferentes setores (multicêntrico), a representação de múltiplos setores (água, energia e alimentos) e atores (políticos, técnicos e leigos), a atuação dentro de escalas ajustadas para a obtenção de resultados e alta intensidade de participação (Hoff, 2011; Allouche et al. 2014; Flammini et al., 2014; Benson et al., 2015; Halbe et al., 2015).

Como a abordagem nexo propõe que a gestão dos recursos seja conduzida de forma interconectada, os arranjos institucionais devem abrigar objetivos que agreguem os interesses de todos os setores. O equilíbrio entre os objetivos setoriais a serem alcançados deve preponderar na mesa de diálogo para que ocorra o engajamento dos atores envolvidos (Flammini et al., 2014; Benson et al., 2015; Pahl-Wostl, 2017).

A gestão dos recursos nexo de modo compartimentalizado e a partir de modelos institucionais do tipo "top-down" resultou em crises e conflitos. O objetivo nexo é buscar coerência na formulação e implementação de políticas e intervenções, promovendo processos participativos que gerem sinergias por meio da ampliação da interação entre as partes interessadas (Hoff, 2011; Allouche et al., 2014).

O caráter multisetorial busca aproximar setores e grupos, que incluem agentes públicos (nacional, estadual e municipal), organizações da sociedade civil, produtores rurais, setor privado, 
dentre outros. A multisetorialidade almeja gerar compartilhamento de valores, visões e informações detidas por cada setor para potencializar a construção de consensos, a resolução de conflitos e decisões mais transparentes e inovadoras (Flammini et al., 2014; Halbe et al., 2015).

A participação de atores que possuem origens e formações distintas possibilita agregar pontos de vistas, aprendizados e conhecimentos fundamentais para se avançar na promoção do desenvolvimento sustentável (Halbe et al., 2015). Especialistas, usuários dos recursos, implementadores de políticas, agentes financeiros são os atores que podem participar da governança nexo (Flammini et al., 2014; Halbe et al., 2015).

A delimitação de uma escala espacial é igualmente relevante para orientar processos de governança nexo, uma vez que cada sistema trabalha sob escalas distintas (Flammini et al., 2014). A atuação orientada por uma escala comum dá sentido à participação dos atores ao contextualizar as problemáticas inter-relacionadas. A escala ideal de intervenção depende de cada realidade, sendo que o nexo está sendo mobilizado sob distintas escalas, a saber: local (municipal, área rural), regional (estados, bacia hidrográfica), nacional, continental e até global (Benson et al., 2015).

Por fim, os arranjos institucionais aptos a conceber a governança nexo demandam alta intensidade de participação. Os arranjos precisam dispor de atribuições deliberativas, onde processos efetivos de negociação e de cogestão dos recursos aconteçam, e que possuam competências decisórias (Flammini et al., 2014). Desse modo, parte-se de que os atores sociais por meio da participação promoverão a gestão eficiente e sustentável dos sistemas de provisão de água, de produção de energia e de alimentos, aumentando o nível de segurança dentro de cada sistema.

\section{Espaços públicos de participação social}

No Brasil, a emergência da sociedade civil demarca o fim de um período autoritário de sucessivos governos militares. O surgimento de novos movimentos sociais, sindicatos, associações e organizações não governamentais reflete a expansão de reivindicações por implantação de espaços de debate e de tomada de decisão para a democratização da gestão das políticas públicas (Dagnino, 2002).

A Constituição Federal de 1988 foi um marco da descentralização das políticas públicas e da abertura destes espaços de participação social. O princípio constitucional de participação, as legislações regulamentadoras das políticas sociais e o processo de descentralização estimularam a implantação de diversos espaços públicos de participação social em nível nacional, estadual e municipal (Jacobi, 2003).

A institucionalização de espaços públicos como aqueles dos conselhos gestores de políticas públicas (saúde, educação, desenvolvimento rural, meio ambiente, etc.) representou a constituição de arranjos institucionais democráticos inovadores. A composição plural de seus membros, representando de forma paritária Estado e sociedade civil, e o caráter deliberativo frequentemente atribuído aos mesmos materializaram a construção de instrumentos da democracia participativa (Jacobi, 2003).

Nesse quadro, a noção de governança expressa um modo de governar mais cooperativo entre os diferentes atores sociais, onde o Estado e os governos deixam de exercer sua autoridade hierárquica sobre o processo de formulação de políticas (Mayntz, 
2001; Billaud, 2014). Desse modo, os indivíduos, grupos ou organizações que possuem algum papel na arena política passam a ser os atores capazes de agir sobre processos públicos de interesse social, tendendo à configuração de redes de atores como forma de agir sobre processos políticos (Mayntz, 2001).

Segundo Buvinich (2014), a participação dos atores sociais nestes espaços almeja de algum modo resultados, por isso o caráter deliberativo destes atores ganhou muita relevância. A possibilidade de a participação dos indivíduos gerar efeitos sobre as decisões políticas representaria um propósito comum (Billaud, 2014; Buvinich, 2014).

No campo das políticas ambientais e de desenvolvimento rural a participação social se tornou elemento constituinte do funcionamento de conselhos gestores municipais, de conselhos de unidades de conservação e de comitês de bacias hidrográficas (Jacobi, 2003). Estes espaços públicos estabeleceram arranjos institucionais para promover a governança relacionada aos recursos naturais (Billaud, 2014). Logo, refletir sobre a governança nexo água, energia e alimentos exige que se considere, primeiro, estes arranjos institucionais como potenciais espaços para abrigá-la.

\section{O nexo água, energia e alimentos no contexto do Sistema Cantareira}

O Sistema Produtor de Água Cantareira é o maior sistema de abastecimento de água da Região Metropolitana de São Paulo, tendo a capacidade de abastecer nove milhões de pessoas. Tal sistema realiza a transposição de águas entre a bacia hidrográfica doadora do Rio Piracicaba e a receptora do
Alto Tietê. Ele tem capacidade de adução de 33 mil litros por segundo, sendo em sua maior parte $\left(31 \mathrm{~m}^{3} / \mathrm{s}\right)$ proveniente desta primeira. A sua área de drenagem de 227,8 mil hectares engloba o território de 12 municípios, sendo quatro no estado de Minas Gerais e oito no de São Paulo (Figura 1).

Em 2011, aproximadamente 62\% da área de contribuição dos reservatórios do Sistema Cantareira sofria influência da pecuária bovina e da silvicultura de eucalipto (Uezu et al., 2017). Logo, o modo como os solos são manejados nestas atividades é um fator que tem relação direta com a infiltração de água, o que se relaciona com a capacidade de recarga dos lençóis freáticos e com a manutenção da vazão de nascentes, córregos e rios, portanto, com o regime hidrológico regional (Lima, 2006).

Ao mesmo tempo, a pecuária bovina se destina à produção de carne e de leite. Cerca de 60\% (2.057) dos estabelecimentos agropecuários dos municípios estudados possuíam cabeças de gado no ano de 2017 (IBGE, 2017). A atividade compõe o conjunto de estratégias econômicas de muitas famílias rurais, além de garantir o abastecimento de alimentos em nível local e regional (Chiodi et al., 2019).

A silvicultura de eucalipto se inter-relaciona com a pecuária, pois é a primeira alternativa de investimento produtivo à pecuária. Os dados disponíveis para os municípios em estudo mostram que em 2017 estavam plantados com eucalipto 45.447 hectares (IBGE, 2017). A monocultura de eucalipto é realizada com diversos fins, mas ressalta-se a produção para a produção de lenha e carvão (Chiodi et al., 2019).

Em suma, mobilizar a abordagem nexo água, energia e alimentos neste contexto consiste em dar centralidade às dimensões ambientais e socioeconômicas em torno das atividades que produzem ali- 
mento e energia. A pecuária bovina e a monocultura de eucalipto demostram importância por ocuparem os solos de modo predominante, por promoverem efeitos sobre as condições hidrológicas locais, por abastecerem mercados e por serem atividades econômicas que compõem as estratégias de reprodução social de parcela significativa da população rural (Chiodi et al., 2019).

Sobre este cenário ainda recaí uma legislação que visa regular o uso do solo e intervir para a recuperação ambiental (Código Florestal, Sistema Nacional de Unidades de Conservação, Lei de Proteção de Mananciais e Lei de Proteção da Mata Atlântica). Assim, a região "produtora de água" para a metrópole paulista se tornou estratégica para atores interessados na conservação ambiental. Atuam nessa região, além dos órgãos ambientais estaduais de São Paulo e de Minas Gerais, prefeituras, várias organizações ambientalistas nacionais e internacionais, universidades públicas e privadas, além de empresas que prestam serviços de assessoria e consultoria socioambiental.

Estes atores com o processo de institucionalização dos espaços públicos de participação passaram a ocupá-los como locus estratégico de atuação para a defesa de seus interesses. Neste campo político-institucional, abriram-se possibilidades para que tais atores passassem a influenciar decisões de interesse público, promovessem o controle social sobre decisões e ações do poder público, fiscalizassem o cumprimento de compromissos legais e apresentassem demandas, influenciando diretamente políticas públicas (Jacobi, 2003; Lüchmann, 2008; Buvinich, 2014).

\section{Características dos espaços públicos de participação}

\subsection{Conselhos gestores municipais}

Nos nove municípios estudados há conselhos gestores de diferentes setores (saúde, educação, turismo, etc.), mas são os de meio ambiente e os de desenvolvimento rural sustentável os que se aproximam da governança nexo, pois possuem competências vinculadas a decisões que afetam o uso e a conservação dos recursos naturais. De modo geral, a criação dos conselhos municipais segue uma mesma lógica, surgem como componentes de novos arranjos institucionais para implementar políticas públicas.

Cada conselho municipal de meio ambiente (COMDEMA) possui um conjunto amplo de objetivos. Em síntese, a legislação analisada aponta para uma convergência dos seguintes objetivos: i) acompanhar e avaliar a execução das políticas e planos municipais de meio ambiente, ii) estabelecer normas neste tema, iii) assessorar o Poder executivo sobre as políticas ambientais, e iv) se posicionar sobre questões de cunho municipal (planejamento e controle do uso do solo, corte de árvores, etc.).

Os conselhos municipais de desenvolvimento rural sustentável (CMDRS) igualmente possuem variados objetivos, mas destacam-se os de aprovar, acompanhar e avaliar a execução das ações previstas nos planos municipais de desenvolvimento rural sustentável. Tais planos estabelecem diagnósticos, objetivos, metas e cronogramas para ações no setor agropecuário. Os técnicos dos órgãos públicos de assistência técnica e extensão rural (ATER) são os principais responsáveis pela elaboração dos planos. 
Estes conselhos são setoriais. O COMDEMA funciona orientado pela legislação ambiental, já o CMDRS se liga mais às questões em volta das cadeias de produção agropecuária. Quase a totalidade dos gestores entrevistados afirmou que a integração entre objetivos e agendas pode ocorrer, mas que quase não acontece. De fato, constatou-se casos em que o conselheiro do COMDEMA não tinha conhecimento da existência do CMDRS e vice-versa. Ainda, a frequência de ocorrência das reuniões é baixa, apesar de variável entre os municípios. Com base nas resoluções dos conselhos, os de meio ambiente realizam reuniões ordinárias mensais ou bimestrais. Os conselhos de desenvolvimento rural realizam mais reuniões bimestrais ou trimestrais.

Os conselhos municipais devem seguir o princípio legal da representação paritária entre estado, município e sociedade civil, o que lhes garantem uma composição multisetorial. A legislação que define a composição dos conselhos municipais mostra que os conselhos de meio ambiente abrigam conselheiros de setores mais diversos como o de Mairiporã, onde o COMDEMA tem membros dos setores de educação, saúde, meio ambiente, obras e serviços, jurídico e turismo. Os conselhos de desenvolvimento rural sustentável comportam principalmente representantes do setor de agricultura das prefeituras, dos órgãos estaduais de ATER e de organizações de produtores, apresentando uma composição eminentemente setorial. Os conselhos municipais pesquisados têm um número mínimo de cinco e máximo de vinte e sete membros.

A legislação que rege estes espaços determina quais setores/grupos terão assento nos conselhos, garantindo a nomeação de atores não estatais e de origem não técnica. Na prática, prevalece terem como presidente ou como secretário executivo um agente estatal. No caso dos COMDEMAs, estes são representantes das prefeituras municipais, e dos CMDRSs, dos órgãos de ATER (Coordenadoria de Desenvolvimento Rural Sustentável - SP e Empresa Estadual de Assistência Técnica e Extensão Rural - MG).

Ressalta-se a restrita presença de produtores rurais nos conselhos de meio ambiente. Nos conselhos de desenvolvimento rural sustentável, embora figurem como conselheiros, no conjunto total dos produtores dos municípios a proporção de participantes é pouco significativa. Como exemplo, Vargem conta com o maior número de vagas em seu CMDRS para produtores rurais, são 13 vagas, mas neste município existem 228 estabelecimentos agropecuários (com uma média de 3,11 pessoas ocupadas por estabelecimento) (IBGE, 2017). Tal proporção, semelhante à maioria dos municípios estudados, indica que os atores que decidem sobre o uso do solo regional pouco participam destes espaços públicos.

Os conselhos municipais são órgãos colegiados de caráter consultivo e deliberativo, mas são pouco propositivos. Aqui, entendeu-se que os COMDEMAs apresentam alta intensidade de participação por terem atribuições que podem gerar impactos sobre políticas ambientais, especialmente a de licenciamento ambiental. Estes têm poderes para permitir, impedir ou embargar empreendimentos (loteamentos, mineração, grandes obras, etc.) que alterem as condições de uso do território municipal. Já os CMDRSs atuam focados em políticas e questões mais particulares aos produtores, portanto, foram considerados como de média intensidade de participação. 


\subsection{Conselhos gestores de unidades de conservação}

O Sistema Nacional de Unidades de Conservação (SNUC - Lei 9.985/2000) define que uma Unidade de Conservação (UC) é um espaço territorial delimitado com seus recursos ambientais, legalmente instituído pelo Poder Público e com objetivos de proteção e conservação (Brasil, 2000). A gestão de uma UC é de responsabilidade do órgão ambiental, seja da esfera federal, estadual ou municipal. Porém, a regulamentação do SNUC (Decreto 4.340/2002) obriga a constituição de conselhos gestores. $\mathrm{O}$ conselho é um fórum de discussão, negociação e gestão da UC. Ao conselho compete acompanhar a elaboração, a implementação e a revisão do plano de manejo da UC, garantindo a participação social (Brasil, 2002). Tal plano estabelece objetivos para a unidade, o seu zoneamento, as normas que devem gerir o uso do território e de manejo dos recursos naturais (Brasil, 2000).

Atuando para cumprir essa regulamentação estão as UCs estaduais da área dos mananciais do Sistema Cantareira. Destacam-se os Parques Estaduais (PE) da Cantareira, do Juquery, de Itapetinga e de Itaberaba; e as Áreas de Proteção Ambiental (APA) Cantareira, Piracicaba Juqueri-Mirim (Área II) e Fernão Dias (Figura 1).

Estas UCs possuem planos de manejo, mas alguns ainda em fase de aprovação (APACantareira, APA Piracicaba Juqueri-Mirim, PE Itaberaba e PE de Itapetinga). Estes planos foram elaborados por empresas de consultoria técnica, que atenderam ao princípio da participação no processo de elaboração. Como identificado nos planos de manejo, os objetivos gerais que motivaram a criação destas
UCs e a elaboração dos seus planos centram-se na proteção na biodiversidade e na conservação dos recursos naturais, enfatizando a importância dos recursos hídricos.

Os conselhos destas UCs são consultivos e compostos por representantes estatais e da sociedade civil (Brasil, 2002). As APAs montam conselhos maiores que chegam à vinte e quatro titulares. Instituiu-se pelo Decreto 4.340/2002 que o gestor da UC é o presidente do conselho. Conforme o presidente do conselho da APA Cantareira, a responsabilidade de compor o conselho é sua como presidente, uma vez que é direcionado a convidar representantes dos municípios, de órgãos estaduais e de organizações da sociedade civil que tenham relação com o território da UC e motivações para cumprir seus objetivos.

Os conselhos investigados estavam compostos por órgãos estaduais (Fundação Florestal-SP, Instituto Estadual de Florestas-MG), municipais (Secretários/Diretores de Meio Ambiente de diferentes municípios) e por organizações da sociedade civil (Organizações não governamentais, empresas privadas, sindicatos e universidades). Mesmo com composições multisetoriais e envolvendo múltiplos atores, estes espaços não somavam a presença de produtores rurais do contexto do Sistema Cantareira.

Dentre as UCs, nenhuma tem território que se sobrepõe exatamente à área dos mananciais do Sistema Cantareira, como pode ser visto na Figura 1. Os territórios dos parques se sobrepõem de forma reduzida à área a jusante do sistema. A APA Fernão Dias e as APAs Piracicaba Juqueri-Mirim e Sistema Cantareira (que são sobrepostas) englobam praticamente toda a área do sistema, mas a extrapolam. A primeira abrange mais quatro municípios, e as duas últimas incluem outros quinze. 
Conforme impõe a legislação, os conselhos destas UCs têm poder de decisão sobre suas formas de funcionamento e seus planos de ação, além de poderem emitir recomendações e se manifestarem sobre assuntos relacionados à gestão da UC (Brasil, 2002). No período da pesquisa, conforme ressaltaram os gestores, nos conselhos das unidades estavam sendo tratados temas mais relacionados ao controle do território e a ações de uso indireto, tais como de comunicação social, de educação ambiental e de pesquisa científica, todas definidas em seus planos de manejo.

Especificamente para as APAs, aponta-se, conforme Prestes et al. (2018), que esta categoria não dispõe de instrumentos legais que exijam de particulares autorização para realizarem a exploração comercial de produtos e serviços a partir dos recursos naturais. Os órgãos ambientais licenciadores não dependem da anuência dos seus conselhos para a aprovação de empreendimentos com potencial poluidor. Somando o caráter consultivo dos conselhos, entendeu-se como limitados para impactar decisões sobre o uso dos recursos naturais, assim, foram tidos como de média intensidade de participação.

\subsection{Comitê de bacia hidrográfica}

A área dos mananciais do Sistema Cantareira está predominantemente sob a gestão do Comitê PCJ. A parcela que se encontra sob a gestão do Comitê do Alto Tietê representa $6 \%$ da sua produção de água. No Comitê PCJ, tal área faz parte do setor leste ("produtor de água") e se localiza a montante da bacia hidrográfica do Rio Piracicaba, onde estão importantes rios da bacia (Rio Jaguari, Rio Cachoeira e Rio Atibainha).
A Política Nacional de Recursos Hídricos (PNRH - Lei 9.433/1997) estabeleceu os princípios da participação, da descentralização e da integração para a gestão dos recursos hídricos (Brasil, 1997). Assim, o objetivo do Comitê PCJ é implementar de modo participativo os instrumentos de gestão dos recursos hídricos, prioritariamente o seu Plano de Bacia (2010-2020). Este possui um conjunto amplo de objetivos específicos, mas centralmente propõe estabelecer o diagnóstico e o plano de ação para compatibilizar a oferta e a demanda de água, em quantidade e qualidade, para todos os pontos da sua bacia hidrográfica. A Agência PCJ é a entidade gerenciadora e executora dos recursos financeiros voltados às ações estabelecidas no Plano das Bacias PCJ.

O Comitê PCJ foi criado em 1993, se tornando referência nacional na implementação do modelo integrado e participativo de gestão dos recursos hídricos. Em suma, a participação social no Comitê ocorre dentro de doze câmaras técnicas (CTs) setoriais que são responsáveis por implementar tal modelo. Na gestão 2017-2019, cada CT comportava em média 30 entidades, chegando a 359 representações dentro das CTs. Ainda, dentro das CTs são criados grupos de trabalho (GTs) com temas e objetivos específicos, havendo 29 GTs em 2019. Estes espaços funcionam a partir de planos de trabalho bianuais que orientam as pautas de reuniões periódicas. A documentação acessada mostra que o Comitê PCJ abre outros espaços de participação em seminários, workshops e audiências públicas, tratando de temas de interesse à gestão da água.

A despeito da respeitada estrutura participativa - acontecem mensalmente dezenas de reuniões, encontros e seminários que aproximam atores de múltiplos setores — , observou-se através da 
análise documental e das reuniões das CTs a dominância de atores de origem técnica. Salienta-se que o secretário executivo do Comitê PCJ tem este perfil e, por longa data, é o mesmo representante do Departamento de Águas e Energia Elétrica do Estado de São Paulo.

Para o Comitê PCJ, a escala de intervenção é a bacia hidrográfica. Ele agrega três bacias hidrográficas (Piracicaba, Capivari e Jundiaí) e a do Rio Piracicaba é de nível federal. São 76 municípios, sendo que apenas dez estão na área de contribuição do Sistema Cantareira. Ou seja, o seu território de intervenção engloba uma enorme diversidade de realidades, setores e atores. Todavia, permite a criação de subcomitês ajustados a escalas ou problemáticas específicas.

O Comitê PCJ é efetivo na gestão dos recursos hídricos. Além do caráter deliberativo, a sua agência de bacia tem autonomia financeira via cobrança pelo uso da água para fomentar iniciativas na bacia hidrográfica, tais como implementar os instrumentos de gestão, criar políticas próprias e financiar obras e projetos. Este espaço coloca múltiplos atores diante de processos de negociação e de cogestão dos recursos hídricos, impondo alta intensidade de participação social.
Por fim, os espaços públicos descritos apresentam características que podem ser consideradas à luz do que se espera de um arranjo institucional apropriado para abrigar a governança nexo água, energia e alimentos, estas sintetizadas na Tabela 2.

\section{Os espaços públicos e a governança nexo água, energia e alimentos}

Oportuno iniciar as discussões com o cenário de fundo do qual emerge a abordagem nexo água, energia e alimentos. No contexto internacional, ela está sendo fomentada pelo Banco Mundial, pela Comissão Europeia e dentro do Fórum Econômico Mundial (Giatti et al., 2016). Conforme Giatti et al. (2016), a forma de colocá-la em prática inclui a ideia de eficiência no uso dos recursos naturais e do uso de mecanismos de mercado para controlar e regular o acesso aos mesmos, aproximando-a da chamada Economia Verde, a qual não focaliza o estímulo a uma reflexão sobre as práticas produtivas insustentáveis e suas possíveis transformações. Ademais, a propagação da abordagem nexo, apesar de assumida como tendo um caráter de aplicabilidade global, ocorre através de instituições científicas

TABELA 2 - Síntese das características dos arranjos institucionais.

\begin{tabular}{llllll}
\hline \multicolumn{1}{c}{ Arranjo } & \multicolumn{1}{c}{ Objetivo institucional } & Setor & Atores & Escala & Intensidade de participação \\
\hline Nexo & Multicêntrico & Multisetorial & Multiatores & $\begin{array}{l}\text { Escala ajus- } \\
\text { tada }\end{array}$ & Alta \\
& Água, energia, alimento & & & & \\
\hline CODEMA & Plano setorial & Multisetorial & Multiatores & Município & Alta \\
\hline CMDRS & Plano setorial & Setorial & Multiatores & Município & Média \\
\hline Conselho de UC & Plano de manejo da UC & Multisetorial & Multiatores & $\begin{array}{l}\text { Território da } \\
\text { UC }\end{array}$ & Média \\
\hline Comitê PCJ & Plano da bacia hidrográfica & Multisetorial & Multiatores & $\begin{array}{l}\text { Bacia hidro- } \\
\text { gráfica }\end{array}$ & Alta \\
\hline
\end{tabular}

FONTE: Elaborado pelo autor. 
e de pesquisadores da Europa, especialmente da Alemanha. Ou seja, a abordagem não emerge de realidades vivenciadas por países em desenvolvimento, como o Brasil.

Contudo, mesmo concordando com estes apontamentos críticos, aqui, defende-se que governança nexo abre novas oportunidades para a expansão e o fortalecimento da democracia participativa para gestão de recursos estratégicos. Portanto, entende-se que ela cria possibilidades para processos adaptados e reflexivos de construção de alternativas às práticas produtivas insustentáveis. Ainda, como é o nosso propósito, permite que seja considerada dentro das realidades político-institucionais locais.

Esse esforço é crível quando se olha para experiências recentes semelhantes. O chamado pagamento por serviços ambientais (PSA) é notório. O PSA surge em contextos internacionais para ser um mecanismo de mercado com o melhor custo/ benefício para se promover a conservação ambiental. Porém, no Brasil, o PSA se tornou amplamente mobilizado como instrumento de política pública e, em vários casos, está reconhecendo e valorizando papéis importantes da agricultura para sociedade, tal como o da gestão sustentável dos recursos naturais (Chiodi \& Moruzzi Marques, 2018).

Partindo destas justificações introdutórias, agora, focaliza-se a análise central do artigo. Primeiramente, entendeu-se que os conselhos gestores municipais, os de unidades de conservação e o comitê de bacia se colocam, a partir dos princípios constitucionais da descentralização e da participação social, como espaços de interesse (Jacobi, 2003; Lüchmann, 2008) à governança nexo. Contudo, mesmo reconhecendo o avanço destes arranjos institucionais para a democracia participativa, estes oportunizam momentos de ação coletiva gerados por uma participação procedimental, portanto, não reivindicada. Em concordância com Billaud (2014), por estarem ligados a um procedimento de política pública, esses dispositivos operam uma lógica instrumental que não se apresenta de início como resultado de um projeto coletivo. Este elemento de origem remete a modelos institucionais "top-down", antagônicos à abordagem nexo por representarem limites à construção de pertencimento e de engajamento dos atores (Allouche et al., 2014; Flammini et al., 2014).

Os espaços públicos estudados são orientados por múltiplos objetivos, mas todos dispõem de planos específicos, o que retrata a dimensão setorial dos mesmos. Com efeito, nenhum deles traz objetivos que integrem interesses e visões compartilhadas entre os provedores de água, de bioenergia e de alimentos. Conforme os membros dos conselhos entrevistados, na prática, a integração entre agendas também não acontece. Tal característica remete ao modelo de gestão setorial (em "silos"), este que é apontado como ineficaz e, portanto, que precisa ser alterado institucionalmente para se possível construir a governança nexo (Hoff, 2011). Em vista disso, a questão que se coloca é: estes arranjos são flexíveis o bastante para acomodar a governança focada no nexo?

Segundo Weitz et al. (2017), para que ocorra a governança nexo, os princípios e objetivos compartilhados pelos atores devem ser bem compreendidos e genuinamente aceitos, condições que exigem processos contínuos e de longo prazo, e que não se reduzem a revisar os objetivos das políticas, seus planos e estratégias. Assim, a flexibilidade institucional coloca-se como elemento para a discussão, pois pode assegurar a efetividade de longo prazo de 
novas instituições para o desenvolvimento sustentável (Corbera et al., 2009).

Por este ângulo, os conselhos gestores apresentam atribuições legalmente estabelecidas no plano de formulação e implementação das políticas públicas (Lüchmann, 2008), sendo este um aspecto da forte normatização dos mecanismos operacionais destes espaços, o que estabelece certa rigidez aos arranjos institucionais participativos (Andrade, 2009). Desse modo, certo grau de inflexibilidade dos arranjos a adaptações ergue-se como um obstáculo à governança nexo água, energia e alimentos.

Os conselhos municipais de meio ambiente e os conselhos das UCs são multisetoriais, porém são limitados por contar com poucos membros. Por outro lado, o Comitê PCJ agrega um número expressivo de entidades de múltiplos setores, inclusive soma a presença da Sabesp (Companhia de Saneamento Básico do Estado de São Paulo, que opera o Sistema e é o ator central do setor hídrico) em nove de suas doze câmaras técnicas, e de setores privados de diferentes ramos, que para Benson et al. (2015) é uma configuração desejável à governança nexo. Todavia, nestes espaços não foram identificados representantes de produtores de alimentos e de bioenergia dos municípios do Sistema Cantareira. Neste sentido, tais espaços públicos que foram instituídos para oportunizar a participação de grupos sociais historicamente excluídos das decisões políticas (Jacobi, 2003) ainda não alcançaram tal propósito. Essa ausência é um dos maiores desafios à governança nexo, no sentido de que ela exige a inclusão de atores não estatais essenciais em seus arranjos de tomada de decisão (Giatti et al., 2016). Além do mais, dentro dos espaços existem posições estratégicas que estavam ocupadas por atores ligados à esfera estatal. Esta realidade expõe o que Andrade (2009) ressaltou como uma fonte de conflitos dentro dos espaços públicos, uma vez que dificulta o estabelecimento do princípio da igualdade de participação entre representantes governamentais e da sociedade. Para a autora, os agentes estatais detêm o monopólio da informação e o controle sobre recursos do Estado, o que lhes garantem um papel privilegiado em negociações e em decisões sobre as políticas públicas.

Os desequilíbrios de poder dentro dos espaços participativos se acentuam com o caráter sociotécnico que estes assumem. Para Billaud (2014), a democracia participativa no campo ambiental se constitui como uma "democracia técnica". Como escreveu:

\begin{abstract}
Na democracia técnica, a objetivação de situações complexas demanda equipamentos cognitivos instrumentos, indicadores, modelos, etc. - que mobilizam as energias e levam a um enquadramento permanente por meio da padronização, o que se revela necessário quando não se quer ficar perdido na infinidade de causas apresentadas para explicar um fenômeno ou um problema. Os problemas ambientais se encaixam bem nessa configuração em que a ciência é requisitada para ordenar causalidades complexas demais, nas quais predomina a incerteza (Billaud, 2014, p. 141-142).
\end{abstract}

Diante disso, é notável o peso dado ao corpo técnico-científico nas relações de força no interior dos espaços de participação, o que pode inibir o envolvimento da comunidade e manter o poder decisório entre os que dominam o conhecimento técnico-científico (Jacobi \& Fracalanza, 2005; Andrade, 2009). No caso estudado, apesar de haver exceções (CMDRS de Nazaré Paulista e de Mairiporã), os presidentes dos conselhos (municipais e UCs) e os 
coordenadores das CTs do Comitê PCJ possuem majoritariamente formação técnica-científica.

Ademais, há uma "concentração participativa”, os mesmos representantes institucionais participam de vários espaços públicos. Como exemplos, o secretário municipal de meio ambiente de Joanópolis é simultaneamente o presidente do COMDEMA, membro do conselho gestor da APA Cantareira, do Comitê PCJ e do Conselho Regional de Desenvolvimento Rural Sustentável; a gestora da APA Fernão Dias é presidente do conselho dessa APA, membro do COMDEMA de Camanducaia, do de Extrema e do Comitê PCJ. Desse modo, além de existir uma grande demanda por participação nos espaços públicos em relação à disponibilidade de representantes institucionais, estes atores participam dominando maior carga de informações sobre as problemáticas regionais, o que favorece posicionamentos mais coerentes nas reuniões.

Neste sentido, Weitz et al. (2017) indicaram a lacuna que há entre a teoria e a prática no domínio do nexo, pois alcançar a coerência que a teoria propõe e estabelecer palcos de negociações equilibrados entre atores, encontra realidades repletas de interesses, representações e agentes com poderes econômicos, sociais e políticos desiguais. No caso aqui analisado, dar início ao enfrentamento de tal realidade exigiria a construção de estratégias e de mecanismos que permitissem conectar atores relevantes à governança nexo, os produtores rurais.

A partir disso, de acordo com Billaud (2014), seria possível mobilizar a expectativa de que o compartilhamento de um ideal de coprodução do "bem comum" poderia reduzir assimetrias de poder e de informação nestes espaços. Porém, agir sob este preceito exigiria evocar um modelo de "coprodução dos saberes", no qual se opera uma valorização dos atores não especialistas, que teriam competências cognitivas e sociais para uma produção de conhecimentos coletivos (Billaud, 2014). Ou seja, exige-se processos que se distanciem da lógica da Economia Verde.

Para apoiar tal expectativa é oportuno apresentar o caso estudado por Billaud (2014) na França. Este autor analisou a implementação de uma política agroambiental com objetivo de efetivar medidas de conservação ambiental em propriedades produtoras de gado no oeste deste país. Dentro de um processo de "democracia técnica", ele enfatizou como no primeiro momento das negociações os produtores de gado eram tecnicamente os leigos ante os representantes das associações de proteção da natureza, das instituições de pesquisa e de políticos. Passados cinco anos de execução da política, tal papel se transforma e os produtores se tornam especialistas em suas próprias práticas, obtendo legitimidade. Para Billaud (2014, p. 154), esta mudança se deveu à proximidade acarretada pelo processo dialógico, como escreveu: "aprende-se a conhecer os outros e, sobretudo, a contornar as relações de poder".

Retornando ao nosso estudo, além da composição multisetorial e multiatores, a escala espacial apropriada se coloca como elemento condutor para a análise do contexto nexo e para a intervenção dos atores (Flammini et al., 2014). Nesta perspectiva, nenhum arranjo institucional adota como escala a área dos mananciais do Sistema Cantareira.

Neste ponto, o Comitê PCJ merece um olhar diferenciado por possuir um arranjo institucional mais compatível e flexível. Compatível porque o comitê tem como unidade de planejamento e gestão a bacia hidrográfica, e flexível porque o Comitê PCJ possui autonomia para criar subcomitês. Tais condições permitiriam conceber um espaço ajustado 
à escala aqui entendida como ideal à governança nexo.

No Comitê PCJ, haveria ainda a flexibilidade para perceber fenômenos que ocorrem em outras escalas (propriedade rural, município, estado, região), expandindo as expectativas de efetividade do modelo nexo (Giatti et al., 2016; Benson et al., 2015). Porém, uma ressalva para a escala da propriedade rural deve ser registrada, pois haveria a necessidade de atentar-se que as territorialidades construídas para identificar os problemas ambientais são distintas daquelas produzidas pelos multipertencimentos dos indivíduos, que têm como referência o espaço da coletividade local (Billaud, 2014). Cardoso (2003) evidenciou também que a definição de bacia hidrográfica por meio de conceitos técnicos e políticos para direcionar políticas participativas de gestão, sem considerar dinâmicas sociais, pode seguramente limitar o sucesso destas políticas pela falta de identidade social que corresponda aos limites da bacia hidrográfica.

Além disso é preciso mais uma vez aproximar a teoria da realidade. Para tanto, considerou-se como o Sistema Cantareira e sua área de influência têm sido tratados dentro do Comitê PCJ. Em 942 atas de reuniões das câmaras técnicas, o termo "Sistema Cantareira" foi registrado em 339 delas (36\%). Embora um tema recorrente, 62\% dos registros relacionaram-se à renovação da outorga do sistema e a informações de seu funcionamento (informes sobre a vazão do sistema dentro CT-MH). Os momentos de renovação da outorga ocorreram entre 2003 e 2004 e entre 2014 e 2017 . Tem-se que estes momentos são como janelas de oportunidade, quando o Comitê PCJ vislumbra estabelecer novas exigências à Sabesp como contrapartida pelo uso da água de sua bacia e espera negociar a captação de um volume maior dessa água para a Região Metropolitana de Campinas (Puga, 2018).

De todo modo, o que este resultado indica é que muitas problemáticas existentes na área dos mananciais do Sistema Cantareira não são prioritárias no interior do Comitê PCJ. As explicações podem ser pela região ser pouco populosa, ou por ter disponibilidade hídrica satisfatória, fazendo com que os problemas dos municípios a jusante sejam assumidos como mais graves e urgentes (exemplo, o saneamento básico).

Para um dos membros entrevistados do Comitê PCJ, a visão do Sistema Cantareira dentro do Comitê mudou ao longo do tempo, bastante influenciada pelo descontentamento com os processos de outorga. Antes entendida como prioritária, a diminuição do interesse na região do Cantareira é explicitada na fala do entrevistado: "Poxa, a gente fica investindo no Cantareira, a água é armazenada e vai tudo para São Paulo [...]. Porque nós vamos investir num negócio que não vem água para nós?". Tal explicação parece ser mais fiel a uma interpretação geral dos atores que representam interesses das regiões central e oeste da bacia PCJ e que não é comumente explicitada em documentos e exposições públicas. Perante esta fala, conclui-se que mesmo havendo a viabilidade para ajustar um espaço que abrigue a governança nexo orientada ao contexto do Sistema Cantareira, a questão que se levanta é: qual o poder de autonomia e de decisão que será possível aos setores e atores dentro deste novo espaço?

Enfim, a última, mas não menos importante característica considerada foi a intensidade de participação que os arranjos institucionais permitem aos atores. Apesar de todos serem espaços participativos, cada arranjo impõe possibilidades distintas da participação gerar e impactar decisões. 
Os conselhos municipais e os de UCs foram apontados pelos gestores como espaços que enfrentam sérias dificuldades para promover a participação e processos de tomada de decisão. As falas transcritas abaixo expressam as principais delas:

Tem que ter no mínimo três pessoas. O complicado é tu ter três pessoas para fazer uma reunião desse Conselho (Conselheiro do CMDRS de Nazaré Paulista, 2019).

O interesse das pessoas também é dificil. Ah tenho interesse em participar. Você convida a pessoa para ser membro do Conselho. Ah! mas eu não tenho tempo[...] (Conselheiro do COMDEMA de Sapucaí-Mirim, 2019).

Então, o Conselho o que que aconteceu. Ele aqui não tinha um produtor no Conselho. Não apareceu ninguém. Nenhum [produtor rural] (Conselheiro do CMDRS de Mairiporã, 2019).

Conseguimos fazer uma reunião só. Nesta reunião eu vi que ele [o Conselho] não é muito atuante, fiz um monte de provação a galera nem aí. Cada um lá tem seu interesse (Gestor do Parque Estadual de Itapetinga, 2019).

A questão é que a gente acaba não sendo propositivo, objetivo. Então não se delibera nada de concreto. Ninguém traz um conteúdo, uma proposta sólida para se debater, para se deliberar, para ter um encaminhamento. E isso acaba sendo um encontro mensal de pessoas discutindo meio ambiente (Conselheiro do CODEMA de Joanópolis, 2019).

Diante destas falas, parte-se do desafio de se realizar as reuniões, estas que são os momentos que materializam e oportunizam a participação. As reuniões ocorrendo normalmente, a ausência de produtores rurais se apresenta como uma lacuna participativa, pois estes são os responsáveis por ações que influenciam o uso do solo. Soma-se a participação passiva dos membros externos ao poder público, fato que reflete em desengajamento e não pertencimento. Por fim, ter reuniões que não geraram ações efetivas torna tais espaços "vazios propositivos".

Mesmo não sendo pertinente generalizar tais dificuldades para todos os conselhos pesquisados, pode-se inferir que estes espaços parecem distantes de poderem abrigar uma participação que gere o diálogo entre os múltiplos atores para construir entendimentos comuns sobre: a) o estado atual dos recursos naturais; b) as tendências esperadas de uso e gerenciamento dos recursos; c) as metas e interesses dos diferentes setores/grupos de usuários em relação à água, energia e alimentos; d) as interações-chave entre os sistemas; e e) as oportunidades de vinculação a processos de tomada de decisão em andamento no contexto de intervenção (Flammini et al., 2014).

Por isso, o Comitê PCJ em relação aos conselhos destaca-se como o mais efetivo na promoção de uma participação ativa e como um espaço de diálogo entre atores, uma vez que as reuniões das CTs e dos GTs ocorrem permanentemente com a expressiva presença de múltiplos atores que seguem planos periódicos de ação e de metas. Nas reuniões observadas, os GTs aparecem ainda como espaços mais favoráveis ao envolvimento dos atores. Como exemplo, o GT-Mananciais acompanha o desenvolvimento da Política de Recuperação, Conservação e Proteção dos Mananciais. A criação deste GT expressa a flexibilidade do Comitê ao possibilitar novos arranjos para atender a demandas específicas, no caso, a gestão de uma política que foi motivada pelos eventos de crise hídrica ocorrida entre 2014 e 2015 . 
Não obstante, este caráter favorável ao Comitê PCJ não é isento de ingerências. Puga (2018) identificou falhas da gestão integrada e participativa da água neste período de crise do Sistema Cantareira. O autor constrói a compreensão de que no auge da crise vários conflitos afloraram, desvelando não somente a disputa entre interesses por trás da gestão hídrica, mas o poder centralizador da Sabesp com o apoio do Governo do Estado de São Paulo. Tal leitura ficou explicitada na aprovação da obra de interligação entre o Sistema Cantareira e a Represa Jaguari na Bacia do Rio Paraíba do Sul. Esta obra, que não constava no Plano Diretor de Abastecimento de Água da Região Metropolitana de São Paulo e apresentou várias contraindicações de ordem técnica, teve oposição de muitos atores dedicados à gestão participativa, tais como o Comitê PCJ, o Comitê da Bacia do Paraíba do Sul, prefeituras municipais e o governo do Estado do Rio de Janeiro. Este episódio expôs problemas em termos da governança da água, de adaptabilidade ao momento de crise, de transparência na tomada de decisões, e o mais sério, de déficit de coordenação entre os atores e níveis institucionais em um cenário anormal de crise (Puga, 2018).

Esta análise demostra o oposto do esperado para a governança nexo, esta que prima pelo diálogo entre múltiplos setores e atores para gerar compartilhamento de valores, visões e informações, tudo para potencializar a construção de consensos, a resolução de conflitos e decisões transparentes (Flammini et al., 2014; Halbe et al., 2015). Portanto, a despeito da estrutura participativa montada pelo Comitê PCJ, este evento demonstrou fragilidades do modelo de gestão integrada e participativa dos recursos hídricos.

Por fim, a questão que se levanta para o contexto da análise é: para ativar um processo de governança nexo água, energia e alimentos seria necessário construir novos arranjos instituicionais ou seria viável induzir esforços para adaptar os preexistentes? (Flammini et al., 2014; Märker et al., 2018).

A segunda opção da questão se torna a nossa resposta. $\mathrm{O}$ comitê de bacia hidrográfica comporta mais características desejáveis para abrigar, ou mesmo incubar, um arranjo institucional apropriado à governança nexo. O Comitê PCJ prioriza a gestão dos recursos hídricos, mas abre oportunidades para integrar de modo equilibrado objetivos relacionados ao uso do solo, à produção de bioenergia e de alimentos. O seu arranjo institucional permite a participação de múltiplos setores e atores sociais. Nele há viabilidade para se ajustar a escala de intervenção, tendo caráter deliberativo e estrutura para impor alta intensidade de participação.

Ademais, o Comitê PCJ é o único espaço que pode atender ao que Pahl-Wostl (2017) defendeu como desejado à governança nexo, combinar modelos de gestão que vão de redes colaborativas, mecanismos de mercado e marcos regulatórios, e ao que Rasul \& Sharma (2016) apontaram como exigências à abordagem, como a coordenação de políticas, o alinhamento de estratégias, regulamentos e incentivos entre os sistemas.

Entretanto, a teoria mais abrangente está distante da realidade complexa dos processos sociais (Weitz et al., 2017), assim os desafios para efetivar a governança nexo água, energia e alimentos são enormes. Dentre todos eles, talvez o principal seja fazer com que os produtores de bioenergia e de alimentos participem ativamente de processos decisórios que conduzam a um desenvolvimento mais sustentável. 


\section{Considerações finais}

A abordagem nexo água, energia e alimentos emerge no âmbito de organizações e fóruns internacionais sob preceitos da Economia Verde. Apesar desta se apresentar como uma concepção acrítica dos modelos produtivos insustentáveis predominantes, o pré-requisito da democracia participativa para a gestão de recursos naturais estratégicos coloca o nexo como uma concepção que pode permitir a ampliação e o fortalecimento da dimensão democrática do desenvolvimento sustentável. Ademais, a perspectiva do nexo abre possibilidades de se construir em contextos locais e regionais a governança sob lógicas que se distanciam dessa Economia Verde, fomentado a participação de atores excluídos e a gestão de recursos naturais como bens comuns e públicos.

No Brasil, os espaços públicos de participação social que surgiram para democratizar a elaboração e a gestão de políticas públicas merecem ser considerados quando se propõe refletir sobre um novo modelo de governança focado no nexo água, energia e alimentos. Para tanto, os arranjos institucionais destes espaços devem ser considerados à luz dos objetivos institucionais, composições de representação (setorial e de atores), escalas de atuação e intensidade de participação que abre aos atores sociais.

Neste sentido, foram analisados espaços públicos na área dos mananciais do Sistema Cantareira, um dos contextos mais críticos à segurança hídrica do país, onde a abordagem nexo está sendo mobilizada para contribuir com a construção de novos modelos de governança socioambiental. Nele, o nexo água, energia e alimentos se vincula às inter-relações que ocorrem no nível do uso e da ocupação do solo, tendo a pecuária bovina e a silvicultura de eucalipto interações no campo socioeconômico, ao mesmo tempo que geram efeitos sobre fatores hidrológicos locais e regionais.

Neste contexto, os conselhos gestores municipais de meio ambiente e de desenvolvimento rural sustentável, os de unidades de conservação e o comitê de bacia hidrográfica possuem características que se alinham ao que se espera de um espaço que abrigue a governança nexo. Porém, da forma como foram desenhados e estão funcionando, nenhum deles comportaria tal proposta. De forma geral, não atuam na escala da área dos mananciais do Sistema Cantareira, são orientados por objetivos setoriais, e, principalmente, não mobilizam produtores rurais.

Especialmente paras os conselhos gestores (de meio ambiente, de desenvolvimento rural sustentável e de unidades de conservação) existem enormes lacunas para que estes possam cumprir com as características gerais de espaços de diálogo para pôr em andamento a governança nexo. Desse modo, o Comitê PCJ se posiciona como o arranjo institucional mais flexível e compatível para abrigar ou incubar um arranjo apropriado à governança nexo, mas esforços seriam exigidos no sentido de criar um subcomitê delimitado pela escala do Sistema Cantareira e de estimular e viabilizar a participação dos atores que são centrais a esta concepção de governança.

A abordagem nexo água, energia e alimentos é bastante recente para os atores sociais que atuam em questões e problemáticas socioambientais no contexto do Sistema Cantareira. Os resultados e conclusões deste artigo procuram não apenas contribuir com a apresentação da abordagem no meio acadêmico, mas estimular que reflexões sejam produzidas almejando as possibilidades efetivas da governança nexo ser aplicada. 


\section{Agradecimentos}

Agradecimento ao Conselho Nacional de Desenvolvimento Científico e Tecnológico do Brasil pelo apoio financeiro [Processo 441244/2017-3].

\section{Referências}

Allouche, J.; Middleton, C.; Gyawal, D. Nexos Nirvana or Nexos Nullity? A dynamic approach to security and sustainability in the water-energy-food nexus, 2014. Disponível em: <https://steps-centre.org/wp-content/uploads/ Water-and-the-Nexos.pdf.> Acesso em: fev. 2019.

Andrade, I. A. L. Conselhos de desenvolvimento rural: um espaço adequado para pensar o desenvolvimento local? In: Schneider, S.; Kunrath, M. S.; Moruzzi Marques, P. E. (Orgs.). Políticas Públicas e participação social no Brasil rural. Porto Alegre: Editora da UFRGS, p. 233-250, 2009.

Benson, D.; Gain, A. K.; Rouillard, J. J. Water Governance in a Comparative Perspective: From IWRM to a 'Nexos' Approach? Water Alternatives, 8 (1), 756-773, 2015. Disponível em: http://www.idaea.csic.es/medspring/sites/default/ files/Water-Governance-in-Comparative-Perspective-From-IWRM-to-a-Nexus-Approach.pdf.

Billaud, J. P. A injunção da participação no campo ambiental ou a questão da incorporação dos "públicos" nos espaços de discussão. Sociologias, 16(35), 138-164, 2014. doi: 10.1590/S1517-45222014000100006.

Brasil. Lei $n .^{\circ}$ 9.433, de 8 de janeiro de 1997. Institui a Política Nacional de Recursos Hídricos. Brasília: DOU de 9/01/1997.

Brasil. Lei $n{ }^{\circ} 9.985$, de 18 de julho de 2000. Institui o Sistema Nacional de Unidades de Conservação da Natureza. Brasília: DOU de 19/07/2000.

Brasil. Decreto n..$^{\circ} .340$, de 22 de agosto de 2002. Regulamenta artigos da Lei ${ }^{\circ}$ 9.985, de 18 de julho de 2000, que dispõe sobre o Sistema Nacional de Unidades de Conservação da Natureza - SNUC, e dá outras providências. Brasília: DOU de 23/08/2002.
Buvinich, D. P. R. O mapeamento da institucionalização dos conselhos gestores de políticas públicas nos municípios brasileiros. Revista de Administração Pública, 48(1), 55-82, 2014. doi: 10.1590/S0034-76122014000100003.

Cardoso, M. L. M. Desafios e potencialidades dos comitês de bacias hidrográficas. Ciência e Cultura, 55(4), 40-41, 2003. Disponível em: http://cienciaecultura.bvs.br/scielo. php?script=sci_arttext\&pid=S0009-67252003000400022.

Chiodi R. E.; Moruzzi Marques, P. E. Multifuncionalidade da agricultura e serviços ambientais: aproximações e distanciamentos como referenciais de políticas públicas. Desenvolvimento em Questão, v. 16(45), 214-232, 2018. doi: 10.21527/2237-6453.2018.45.

Chiodi, R. E.; Faraco, A. N.; Uezu, A. O contexto nexos água, energia e alimento na área de contribuição do Sistema Produtor de Água Cantareira. In: Anais do Congresso da SOBER. Ilhéus, 23 de jul., 2019.

Corbera, E.; Soberanisc, C.; Brown, K. Institutional dimensions of Payments for Ecosystem Services: An analysis of Mexico's carbon forestry programme. Ecological Economics, 68(3), 743-761, 2009. doi: 10.1016/j.ecolecon.2008.06.008.

Dagnino, E. Sociedade Civil, Espaços Públicos e Construção Democrática no Brasil: Limites e Possibilidades. In: Dagnino, E. Org.). Sociedade civil e espaços públicos no Brasil. São Paulo: Paz e Terra, p. 279-301, 2002.

Flammini A. Walking the nexos talk: assessing the waterenergy-food nexos in the context ofthe sustainable energy for all initiative, 2014. Disponível em: <http://www.fao. org/3/a-i3959e.pdf. Acesso em: out. 2018.

Giatti, L. L.; Jacobi, P. R.; Favaro, A. K. M.; Empinotti, V. L. O nexo água, energia e alimentos no contexto da Metrópole Paulista. Estudos Avançados, 30(88), 43-61, 2016. doi: $10.1590 / \mathrm{s} 0103-40142016.30880005$.

Halbe, J.; Pahl-Wostl, C.; Lange, M. A.; Velonis, C. Governance of transitions towards sustainable development - the water-energy-food nexus in Cyprus. Water International, 40 (5-6), 877-894, 2015. doi: 10.1080/02508060.2015.1070328.

Hall, P. A.; Taylor, R. C. R. As três versões do neo-institu- 
cionalismo. Lua Nova, 58, 193-224, 2003. Disponível em: https://www.scielo.br/pdf/ln/n58/a10n58.pdf.

Hoff, H. Understanding the Nexos. Background Paper for the Bonn 2011 Conference, 2011. Disponível em: <https:// www.water-energy-food.org/uploads/media/understanding_the_nexos.pdf $>$. Acesso em: jun. 2019.

IBGE - Instituto Brasileiro de Geografia e Estatística. Censo Agropecuário 2017. Disponível em: https://censos.ibge.gov. br/agro/2017/. Acesso em: 20 mar. 2018.

Jacobi, P. R. Espaços públicos e práticas participativas na gestão do meio ambiente no Brasil. Sociedade e Estado, 18(1/2), 315-338, 2003. doi: 10.1590/S010269922003000100015.

Jacobi, P. R.; Fracalanza, A. P. Comitês de bacias hidrográficas no Brasil: desafios de fortalecimento da gestão compartilhada e participativa. Desenvolvimento e Meio Ambiente, 11-12, 41-49, 2005. Disponível em: https://revistas.ufpr.br/ made/article/view/7816. Acesso em: jan. 2020.

Keskinen, M.; Someth, P.; Salmivaara, A.; Kummu, M. Water-Energy-Food Nexus in a Transboundary River Basin: The Case of Tonle Sap Lake, Mekong River Basin. Water, 7, 5416-5436, 2015. doi.org/10.3390/w7105416

Lima, W. P. Efeitos hidrológicos do manejo de florestas plantadas. In: Lima, W. P.; Zakia, M. B. J. (Orgs.). As florestas plantadas e a água. São Carlos: RIMA/CNPq, p. 10-28, 2006.

Lüchmann, L. H. H. Participação e representação nos conselhos gestores e no orçamento participativo. Caderno do CRH, 21(52), 87-97, 2008. doi: 10.1590/S010349792008000100007.

Märker, C.; Venghaus, S.; Hake, J. F. Integrated governance for the food-energy water nexus - The scope of action for institutional change. Renewable and Sustainable Energy Reviews, 97, 290-300, 2018. doi: 10.1016/j.rser.2018.08.020.

Mayntz, R. El Estado y la sociedade civil em la gobernanza moderna. Revista del CLAD Reforma y Democracia, 21, 1-8, 2001. Disponível em: http://www.lasociedadcivil.org. Acesso em: dez. 2019.

Pahl-Wostl, C. A conceptual framework for analysing adaptive capacity and multilevel learning processes in resource governance regimes. Global Environmental Change, 19, 354-365, 2009. doi: 10.1016/j.gloenvcha.2009.06.001.

Pahl-Wostl, C., Governance of the water-energy-food security nexos: A multi-level coordination challenge. Environmental Science and Policy, 8(1), 356-367, 2017. doi: 10.1016/j.envsci.2017.07.017.

Prestes, L. D.; Perello, L. F. C.; Gruber, N. L. S. Métodos para avaliar efetividade de gestão: o caso particular das Áreas de Proteção Ambiental (APAs). Desenvolvimento e Meio Ambiente, 44, 340-359, 2018. Disponível em: https:// revistas.ufpr.br/made/article/view/54880. Acesso em: mar. 2020.

Puga, B. P. Governança dos recursos hídricos e eventos climáticos extremos: a crise hídrica de São Paulo. Campinas, Tese (Doutorado em Desenvolvimento Econômico) - UNICAMP, 2018.

Rasul, G.; Sharma, B. The nexos approach to water-energy-food security: an option for adaptation to climate change. Climate Policy, 16(6), 682-702, 2016. doi: 10.1080/14693062.2015.1029865.

Richardson, R. J. Pesquisa social: métodos e técnicas. São Paulo: Atlas, 2. ed., 2010.

Scott, A. Making governance work for water-energy-food nexos approaches, 2017. Disponível em: $<\mathrm{https} / / / \mathrm{cdkn}$. org/resource/working-paper-making-governance-work-water-energy-food-nexos-approaches/?loclang=en_gb>. Acesso: mar. 2019.

Uezu, A.; Sarcinelli, O.; Chiodi, R. E.; Jenkins, C, N.; Martins, C. S. Atlas dos serviços ambientais do Sistema Cantareira. São Paulo: Instituto de Pesquisas Ecológicas, 2017.

Weitz, N.; Strambo, C.; Kemp-Benedict, E.; Nilsson, M. Closing the governance gaps in the water-energy-food nexus: Insights from integrative governance. Global Environmental Change, 45, 165-173, 2017. doi: 10.1016/j. gloenvcha.2017.06.006. 